\title{
Outcome Determinants of Stroke in a Brazilian Primary Stroke Center
}

\author{
Gustavo W. Kuster, ${ }^{1,2,3}$ Lívia A. Dutra, ${ }^{1,2,4}$ Israel P. Brasil,, ${ }^{1,2}$ Evelyn P. Pacheco, ${ }^{1,2}$ \\ Márcio A. C. Arruda, ${ }^{1}$ Cristiane Volcov, ${ }^{1,2}$ and Renan B. Domingues ${ }^{1,2,5}$ \\ ${ }^{1}$ Hospital Paulistano, 01321-001 São Paulo, SP, Brazil \\ ${ }^{2}$ Stroke Integrated Program (PIAVEN), Amil Stroke Network, 01321-001 São Paulo, SP, Brazil \\ ${ }^{3}$ Department of Neurology, Faculdade de Medicina do ABC, 09060-650 Santo André, SP, Brazil \\ ${ }^{4}$ Department of Neurology, Federal University of São Paulo (UNIFESP), 04021-001 São Paulo, SP, Brazil \\ ${ }^{5}$ Neurosciences Program, Federal University of Minas Gerais (UFMG), 31270-901 Belo Horizonte, MG, Brazil
}

Correspondence should be addressed to Gustavo W. Kuster; gwkuster@hotmail.com

Received 1 November 2014; Accepted 26 November 2014; Published 11 December 2014

Academic Editor: Graeme Hankey

Copyright (C) 2014 Gustavo W. Kuster et al. This is an open access article distributed under the Creative Commons Attribution License, which permits unrestricted use, distribution, and reproduction in any medium, provided the original work is properly cited.

Background. Stroke mortality in Brazil is one of the highest among Western countries. Nonetheless, stroke outcome determinants are still poorly known in this country. In this study we evaluate outcome determinants of stroke in a primary stroke center in São Paulo, Brazil. Methods. We evaluated demographic, clinical, and outcome data of patients with ischemic stroke (IS), transient ischemic attack (TIA), and intracerebral hemorrhage (ICH) admitted at "Hospital Paulistano," São Paulo, Brazil. In-hospital mortality and functional outcome determinants were assessed. Univariate and binary logistic regression analysis were performed. Results. Three hundred forty-one patients were included in the study, $52.2 \%$ being male with $66.8 \pm 15.7$ years. The stroke type distribution was IS: $59.2 \%$, TIA: $29.6 \%$, and ICH: $11.1 \%$. ICH was associated with greater severity and poorer functional outcome. The determinants of poorer functional outcome were higher NIHSS, lower Glasgow score, and lower oxygen saturation level. The most important mortality determinant was the presence of visual symptoms. Conclusions. The stroke mortality and stroke outcome determinants found in the present study do not remarkably differ from studies carried out in developed countries. Stroke prognosis studies are crucial to better understand the high burden of stroke in Brazil.

\section{Introduction}

Stroke is the first cause of disability, the second cause of cognitive impairment, and the third cause of death in the world [1]. Two-thirds of all stroke deaths occur in low- and middle-income countries, including Latin America countries; however, stroke has been poorly studied in these regions [2]. In Brazil, the largest country in the region, stroke is the leading cause of death and disability and the stroke mortality is one of the highest among Western countries $[3,4]$.

The causes of the high stroke burden in Brazil remain speculative. One possibility is that the prevalence of stroke is higher in Brazil than in other regions. Some prevalence studies were carried in Brazil but the data are not sufficient to provide an overview of stroke prevalence in Brazil, since most of these studies were carried out in specific regions that do not necessarily reflect the whole country reality [5]. Other potential explanations rely on medical assistance deficiencies, mostly driven by socioeconomic inequality. In fact, previous studies showed that the majority of patients are assisted in public hospitals where diagnostic and therapeutic resources are scarce [6-9]. However, the negative impact of these discrepancies on stroke outcome in Brazil still requires confirmation by large population studies. At this point few studies have evaluated stroke outcome [7-10] in Brazil and the outcome determinants of stroke in Brazil are still poorly known. 
Several variables including the higher score with $\mathrm{NIH}$ Stroke Scale (NIHSS), higher age, atrial fibrillation, hypertension, diabetes mellitus, lower level of consciousness, higher time between stroke onset and admission, and the presence of visual field abnormalities at the first evaluation have been considered predictors of stroke poor outcome [11-16]. Most of the outcome determinants studies were carried out in developed or Asian countries.

The aim of the present study was to evaluate stroke prognosis and stroke prognosis determinants in a population of stroke patients seen in a primary stroke center in São Paulo, the largest Brazilian city.

\section{Methods}

This study was carried out between 2012 and 2014 at Hospital Paulistano, a Joint Commission International certified stroke center located in the central region of São Paulo, Brazil. This study protocol was approved by the Ethics Committee on Research of Hospital Paulistano (Amil Stroke Network) and informed consent was obtained from each participant or legal representative.

2.1. Patients and Procedures. Patients that presented to the emergency room with suspected stroke were evaluated by a neurologist at admission and submitted to a standardized protocol. Demographical data, time delay between stroke onset and admission, stroke warning symptoms (weakness and numbness, confusion, speech difficulties, comprehension problems, vision abnormalities, walking troubles, severe headache, dizziness, and incoordination), and stroke risk factors (hypertension, smoking, contraceptive use, obesity, familial history, diabetes, previous stroke, or transient ischemic attack) were compiled. We also collected the following data at admission: vital signs, capillary glucose, oxygen saturation levels, Glasgow coma scale score, and National Institutes of Health Stroke Scale (NIHSS).

After initial evaluation patients were submitted to noncontrast brain CT with $10-\mathrm{mm}$ slice thickness and radiological findings (detectable brain infarct, dense artery sign, local intracerebral hemorrhage, distant brain hemorrhage, and cerebral edema) were recorded. Patients were diagnosed as having ischemic stroke (IS), transient ischemic attack (TIA), intracerebral hemorrhage (ICH), or subarachnoid hemorrhage (SHA) according to previously established definitions [17]. Data of IS treatment including thrombolytic therapy, the use of antithrombotic agents in the first 48 hours, and venous thrombosis prophylaxis were collected. Patients without confirmed stroke and patients with SHA were not included. The outcome determinants analysis was carried exclusively in the groups of patients with confirmed IS or ICH.

2.2. Statistical Analysis. Statistical analysis was performed using SPSS version 15.0 for Windows. The confidence interval was of $95 \%$ and the significance level was set at $P<0.05$. Normality was assessed using the Kolmogorov-Smirnov test. Student's $t$-test was used for continuous data and categorical
TABle 1: Demographical, clinical, and radiological data of the 341 patients included in the study.

\begin{tabular}{|c|c|}
\hline Characteristics & Findings \\
\hline Age $($ mean $\pm \mathrm{SD})$ & $66.8 \pm 15.7$ years \\
\hline \multicolumn{2}{|l|}{ Gender } \\
\hline Male (\%) & 52.2 \\
\hline Female (\%) & 47.8 \\
\hline \multicolumn{2}{|l|}{ Type of stroke } \\
\hline IS (\%) & 59.2 \\
\hline TIA (\%) & 29.6 \\
\hline $\mathrm{ICH}(\%)$ & 11.1 \\
\hline Previous hypertension (\%) & 68 \\
\hline Diabetes $(\%)$ & 37 \\
\hline Previous stroke (\%) & 26.4 \\
\hline Smoking (\%) & 14 \\
\hline Obesity (\%) & 7.9 \\
\hline Familial history of stroke (\%) & 7 \\
\hline $\begin{array}{l}\text { Time of symptoms at arrival } \\
(\text { mean } \pm \text { SD })\end{array}$ & $1661 \pm 3979$ minutes \\
\hline Wake-up stroke $(\%)^{*}$ & 25.2 \\
\hline \multicolumn{2}{|l|}{ Stroke warning symptoms* } \\
\hline Weakness and numbness (\%) & 66.6 \\
\hline $\begin{array}{l}\text { Confusion, speech difficulties, and } \\
\text { comprehension problems (\%) }\end{array}$ & 39 \\
\hline Dizziness and incoordination (\%) & 19.6 \\
\hline Severe headache $(\%)$ & 16.7 \\
\hline Walking troubles $(\%)$ & 16.4 \\
\hline Vision abnormalities (\%) & 11.1 \\
\hline $\begin{array}{l}\text { Systolic blood pressure (mean } \pm \\
\text { SD)* }\end{array}$ & $148.9 \pm 54.1 \mathrm{~mm} \mathrm{Hg}$ \\
\hline $\begin{array}{l}\text { Diastolic blood pressure } \\
(\text { mean } \pm \mathrm{SD})^{*}\end{array}$ & $84.1 \pm 42.8 \mathrm{~mm} \mathrm{Hg}$ \\
\hline Heart rate $(\text { mean } \pm \mathrm{SD})^{*}$ & $80.8 \pm 15.9$ beats per minute \\
\hline $\begin{array}{l}\text { Oxygen saturation level } \\
(\text { mean } \pm S D)^{*}\end{array}$ & $95.9 \pm 3 \%$ \\
\hline Capillary glycemia $(\text { mean } \pm \mathrm{SD})^{*}$ & $137.1 \pm 56.1 \mathrm{mg} / \mathrm{dL}$ \\
\hline Temperature $(\text { mean } \pm S D)^{*}$ & $35.9 \pm 2.9$ Celsius \\
\hline Glasgow score $(\text { mean } \pm \mathrm{SD})^{*}$ & $14.1 \pm 2.3$ \\
\hline NIHSS at admission* & $\begin{array}{c}\text { Median }=2, \text { interquartile } \\
\text { range }=5\end{array}$ \\
\hline NIHSS at discharge ${ }^{* *}$ & $\begin{array}{c}\text { Median }=0, \text { interquartile } \\
\text { range }=2\end{array}$ \\
\hline
\end{tabular}

${ }^{*}$ Data obtained at the first evaluation; ${ }^{* *}$ data obtained at discharge; IS: ischemic stroke; ICH: intracerebral hemorrhage; TIA: transient ischemic attack; NIHSS: National Institutes of Health Stroke Scale.

data were compared using Chi-square analyses. In-hospital mortality and modified Rankin score (mRs) at discharge, whereby the patients were divided into two groups, one with $\mathrm{mRs} \leq 2$ and other with $\mathrm{mRs}>2$, were defined as outcomes measures. Binary logistic regression analysis was 
TABLE 2: Comparison of clinical and radiological data according to the modified Rankin score (mRs) at discharge.

\begin{tabular}{|c|c|c|c|c|}
\hline & $\begin{array}{c}\mathrm{mRs} \leq 2 \\
(N=157)\end{array}$ & $\begin{array}{c}\mathrm{mRs}>2 \\
(N=73)\end{array}$ & $P$ & $P^{*}$ \\
\hline Age & $65.1 \pm 15.5$ & $72.2 \pm 15$ & $<0.001$ & 0.398 \\
\hline Male & $90(39.1 \%)$ & $36(15.7 \%)$ & 0.256 & - \\
\hline Smoking & $25(10.1 \%)$ & $9(3.9 \%)$ & 0.463 & - \\
\hline Hypertension & $105(45.7 \%)$ & $58(25.2 \%)$ & 0.061 & - \\
\hline Obesity & $15(6.5 \%)$ & $7(3 \%)$ & 0.993 & - \\
\hline Family history & $12(5.2 \%)$ & $4(1.7 \%)$ & 0.548 & - \\
\hline Diabetes & $60(26.1 \%)$ & $29(12.6 \%)$ & 0.827 & - \\
\hline Previous stroke & $42(18.3 \%)$ & $19(8.3 \%)$ & 0.908 & - \\
\hline Weakness and numbness & $109(47.4 \%)$ & $54(23.5 \%)$ & 0.307 & - \\
\hline Confusion, speech difficulties, and comprehension problems & $53(23 \%)$ & $38(16.5 \%)$ & 0.017 & 0.130 \\
\hline Vision abnormalities & $24(10.4 \%)$ & $2(0.9 \%)$ & 0.012 & 0.998 \\
\hline Walking troubles & $22(9.5 \%)$ & $18(7.8 \%)$ & 0.071 & - \\
\hline Severe headache & $27(11.7 \%)$ & $7(3 \%)$ & 0.147 & - \\
\hline Dizziness and incoordination & $33(14.3 \%)$ & $11(4.8 \%)$ & 0.239 & - \\
\hline CT detectable brain infarct & $25(10.9 \%)$ & $20(8.7 \%)$ & 0.035 & 0.778 \\
\hline CT dense artery sign & $3(1.3 \%)$ & $7(3 \%)$ & 0.073 & - \\
\hline Cerebral edema & $4(1.7 \%)$ & $11(4.8 \%)$ & 0.004 & 1.000 \\
\hline Wake-up stroke & $35(15.2 \%)$ & $26(11.3 \%)$ & 0.068 & - \\
\hline SBP & $147.3 \pm 25.8$ & $147.2 \pm 29.5$ & 0.973 & - \\
\hline DBP & $86.8 \pm 60.4$ & $84.5 \pm 15$ & 0.745 & - \\
\hline $\mathrm{HR}$ & $80.4 \pm 15.5$ & $81.8 \pm 19.3$ & 0.563 & - \\
\hline Sat $\mathrm{O} 2$ & $96.5 \pm 2.1$ & $94.4 \pm 4.5$ & $<0.001$ & 0.026 \\
\hline Temperature & $35.9 \pm 2.9$ & $35.6 \pm 4.4$ & 0.555 & - \\
\hline Digital glycemia & $130.8 \pm 50.1$ & $148.7 \pm 62$ & 0.040 & 0.846 \\
\hline Time of symptoms & $1359.6 \pm 2697$ & $1850.8 \pm 4091.4$ & 0.330 & - \\
\hline Glasgow (initial) & $14.7 \pm 1.4$ & $13.1 \pm 3.2$ & $<0.001$ & 0.008 \\
\hline NIHSS (initial) & Median $=1, \mathrm{IR}=3$ & Median $=12, \mathrm{IR}=14$ & $<0.001$ & $<0.001$ \\
\hline
\end{tabular}

CT: computed tomography; SBP: systolic blood pressure; DBP: diastolic blood pressure; HR: heart rate; Sat O2: oxygen saturation; NIHSS: National Institutes of Health Stroke Scale; IR = interquartile range; $P$ : according to $t$-test (continuous variables) or Chi-square test (categorical variables); $P^{*}$ : according to binary logistic regression analysis with significant variables.

performed after excluding nonsignificant variables with inhospital mortality and discharge Rankin modified score as dependent variables.

\section{Results}

Demographic data, stroke risk factors, stroke warning symptoms, and clinical data from the 341 patients included in the study are shown in Table 1.

The therapeutic measures adopted in patients with brain ischemia were as follows: twenty-seven out of the 202 patients with IS (13.4\% of all IS patients) were treated with thrombolytic treatment, 18 (8.9\%) with intravenous and $9(4.4 \%)$ with endovascular therapy. Two hundred fifty-eight out of 303 patients with IS and TIA (85.1\%) received antithrombotic therapy within 48 hours after stroke and $93.1 \%$ of the group of patients with either IS or TIA received venous thrombosis prophylactic treatment. Among ICH patients, nine $(23.7 \%)$ were submitted to surgical treatment and the others received conservative treatment.

When comparing the clinical features and outcome of patients with IS and ICH, we found that patients with $\mathrm{ICH}$ had a more severe disease than patients with IS. Patients with IS had higher diastolic blood pressure (IS: $82 \pm 15.6$, ICH: $100.9 \pm 120, P=0.011$ ), lower oxygen saturation levels (IS: $96 \pm 2.7$, ICH: $94.9 \pm 4.5, P=0.038)$, and lower Glasgow score at admission (IS: $14.3 \pm 1.9, \mathrm{ICH}: 12.5 \pm 3.8, P<0.001$ ). At discharge patients with ICH had higher NIHSS scores ( IS median $=0$, interquartile range $=2$, ICH median $=2.5$, interquartile range $=10$, and $P<0.001$ ) and higher mRS (IS median $=0$, interquartile range $=2, \mathrm{ICH}$ median $=1.5$, interquartile range $=4$, and $P<0.001$ ).

The outcome measures were evaluated in patients with IS and ICH. Twenty-eight out of 315 patients (8.9\%) died during hospitalization, $23(8.2 \%)$ of the patients with IS and $5(13.9 \%)$ of the patients with $\mathrm{ICH}(P=0.256)$. At hospital discharge 
TABLE 3: Comparison of clinical and radiological data of survivors and patients that died during hospitalization.

\begin{tabular}{|c|c|c|c|c|}
\hline & $\begin{array}{l}\text { Survivors } \\
(N=287)\end{array}$ & $\begin{array}{l}\text { In-hospital death } \\
\quad(N=28)\end{array}$ & $P$ & $P^{*}$ \\
\hline Age & $66.4 \pm 15.8$ & $68.5 \pm 16.7$ & 0.509 & - \\
\hline Male & $156(49.5 \%)$ & $15(4.8 \%)$ & 0.555 & - \\
\hline Smoking & $44(14 \%)$ & $4(1.3 \%)$ & 0.904 & - \\
\hline Hypertension & $194(61.6 \%)$ & $22(7 \%)$ & 0.361 & - \\
\hline Obesity & $23(7.3 \%)$ & $4(12.7 \%)$ & 0.498 & - \\
\hline Family history & $20(6.3 \%)$ & $2(0.6 \%)$ & 0.001 & - \\
\hline Diabetes & $107(34 \%)$ & $9(2.8 \%)$ & 0.652 & - \\
\hline Previous stroke & $75(23.8 \%)$ & $9(2.8 \%)$ & 0.189 & - \\
\hline Weakness and numbness & $192(60.9 \%)$ & $19(6 \%)$ & 0.179 & - \\
\hline Confusion, speech difficulties, and comprehension problems & $111(35.2 \%)$ & $10(3.2 \%)$ & 0.121 & - \\
\hline Vision abnormalities & $27(8.6 \%)$ & $7(2.2 \%)$ & 0.024 & 0.018 \\
\hline Walking troubles & $47(14.9 \%)$ & $5(1.6 \%)$ & 0.072 & - \\
\hline Severe headache & $48(15.2 \%)$ & $7(2.2 \%)$ & 0.135 & - \\
\hline Dizziness and incoordination & $60(19 \%)$ & $5(15.9 \%)$ & 0.064 & - \\
\hline CT detectable brain infarct & $56(17.8 \%)$ & $7(2.2 \%)$ & 0.538 & - \\
\hline CT dense artery sign & $13(4.1 \%)$ & $3(0.9 \%)$ & 0.005 & 0.599 \\
\hline Cerebral edema & $18(5.7 \%)$ & $2(0.6 \%)$ & 0.002 & 1.000 \\
\hline Wake-up stroke & $78(24.8 \%)$ & $4(1.3 \%)$ & 0.282 & - \\
\hline SBP & $150.2 \pm 58$ & $142.1 \pm 24.7$ & 0.165 & - \\
\hline DBP & $84.8 \pm 46.2$ & $81.8 \pm 15.6$ & 0.463 & - \\
\hline HR & $80.7 \pm 15.8$ & $78.2 \pm 19.5$ & 0.516 & - \\
\hline Sat $\mathrm{O} 2$ & $95.8 \pm 3.2$ & $96.5 \pm 2.4$ & 0.180 & - \\
\hline Temperature & $35.9 \pm 3.1$ & $36 \pm 0.4$ & 0.460 & - \\
\hline Digital glycemia & $136.6 \pm 55$ & $122 \pm 33.9$ & 0.100 & - \\
\hline Time of symptoms & $1777.7 \pm 4215.2$ & $773.25 \pm 1180.7$ & 0.009 & 0.252 \\
\hline Glasgow (initial) & $5.4 \pm 7.5$ & $6 \pm 7.6$ & 0.685 & 0.293 \\
\hline NIHSS (initial) & Median $=2, \mathrm{IR}=8$ & Median $=2, \mathrm{IR}=10$ & 0.694 & 0.125 \\
\hline
\end{tabular}

CT: computed tomography; SBP: systolic blood pressure; DBP: diastolic blood pressure; HR: heart rate; Sat O2: oxygen saturation; NIHSS: National Institutes of Health Stroke Scale; IR = interquartile range; $P$ : according to $t$-test (continuous variables) or Chi-square test (categorical variables); $P^{*}$ : according to binary logistic regression analysis with significant variables.

$31.7 \%$ of the survivors had $\mathrm{mRs}>2,28.1 \%$ of the IS patients and $62.5 \%$ of ICH patients $(P<0.001)$. Tables 2 and 3 show the comparisons of characteristics of patients according to the outcome measures. After binary regression analysis the only variables significantly associated with $\mathrm{mRs}>2$ at discharge were ICH diagnosis $(P<0.001)$, lower oxygen saturation $(P=0.026)$, lower Glasgow score $(P=0.008)$, and higher NIHSS at onset $(P<0.001)$. The only variable associated with in-hospital death was the presence of vision field abnormality at admission $(P=0.018)$.

\section{Discussion}

To our knowledge this was the first study to evaluate outcome determinants in a Brazilian primary stroke center. We found that lower Glasgow score, lower NIHSS, and lower oxygen saturation were independently associated with poorer functional outcome and that visual symptoms at onset were independently associated with in-hospital mortality.
These findings are in line with previous studies. NIHSS has been demonstrated as one of the most important outcome predictors among patients with IS [13-16]. Reduced level of consciousness and reduced Glasgow score were found to be associated with poorer outcome in patients with IS [16] and in patients with ICH $[18,19]$. Lower oxygen saturation at admission is inversely correlated with stroke prognosis [20]. Visual field abnormalities were associated with unfavorable outcome in patients with IS in a previous study [16]. The association of visual symptoms with poorer outcome could be related with posterior circulation involvement, explaining the worse outcome. Other variables were previously associated with poorer outcome: age, hypertension, diabetes and glucose level at admission, CT hyperdense artery sign, and CT hypointensity $[16,21,22]$. In our study some variables were associated with outcome only by univariate analysis. Patients with poorer functional outcome were of higher age and had higher glucose level, more frequent confusion, vision abnormalities, CT hypodensity, and cerebral edema; however, 
these differences were not significant after adjusted analysis. CT dense artery sign and cerebral edema were more frequent among those who died during hospitalization; however, these differences were no longer significant after regression analysis. It is possible that the small sample size in the present study did not allow the demonstration of other significant differences.

The mean stroke age we found was similar to what was found in a recent study in United States [23]. ICH proportion and ICH severity were similar to previous descriptions [24]. The therapeutic measures registered here are in accordance with stroke care quality indicators. The percentage of IS patients treated with TPA in our study was even higher than in previous population studies [25], probably reflecting the fact that our study was carried in a single institution with 24hour neurologist and a stroke protocol. The rate of patients that received antithrombotic therapy within the first 48 hours after stroke $(85.1 \%)$ and the rate of patients submitted to venous thrombosis prophylactic treatment (93.1\%) are similar to what was previously reported in US hospitals $[26,27]$ and in other private hospitals in Brazil [28]. The in-hospital mortality rate registered here was not discrepant from previous studies in developed countries [29]. Overall these data suggest that the clinical, therapeutic, and outcome characteristics of the population of the present study do not remarkably differ from stroke populations in developed countries. It is likely that this reflects the fact that the present study was carried out in a private institution, with availability of all stroke validated therapies. Our hospital serves predominantly middle and upper middle class patients. The emergence service of our hospital has a neurologist 24 hours a day, 7 days a week, a nurse in charge of the management of stroke cases, intensive care unit, 24-hour CT scan, magnetic resonance imaging, and an interventional neuroradiology service available 24 hours a day, 7 days a week. It is a primary stroke center certified by Joint Commission International that follows the American Heart Association guidelines. Considering the specificities of our service, large and multicentric studies are still needed to determine if the outcome of stroke among patients assisted in public Brazilian hospitals differs from private hospitals.

Our study has some limitations that deserve to be mentioned. We analyzed a small and a single center sample. Our results need confirmation in larger and multicentric studies involving different Brazilian regions with different socioeconomic levels. Another limitation is that this study did not include follow-up of the patients and we evaluated only in-hospital outcomes, while most of the prognostic studies assess three-month outcome. Future outcome studies should address long-term outcome in patients with stroke in Brazil. As strengths of this study the population was homogeneous and the same stroke team assisted all the patients following the same stroke protocols.

In conclusion, the present study was the first to specifically assess outcome determinants in a Brazilian primary stroke center with availability of all current validated stroke therapies. The outcome and outcome determinants reported in the present study shared great similarities with previous studies in developed countries. Population studies are still necessary to better understand the great burden of stroke in Brazil.

\section{Disclosure}

Dr. Renan B. Domingues is a recipient of a CAPES Domingues is a recipient of a CAPES postdoctoral scholarship.

\section{Conflict of Interests}

The authors declare that there is no conflict of interests regarding the publication of this paper.

\section{References}

[1] G. J. Hankey and C. P. Warlow, "Treatment and secondary prevention of stroke: evidence, costs, and effects on individuals and populations," The Lancet, vol. 354, no. 9188, pp. 1457-1463, 1999.

[2] P. M. Lavados, A. J. Hennis, J. G. Fernandes et al., "Stroke epidemiology, prevention, and management strategies at a regional level: Latin America and the Caribbean," The Lancet Neurology, vol. 6, no. 4, pp. 362-372, 2007.

[3] P. A. Lotufo, A. C. Goulart, T. G. Fernandes, and I. M. Benseñor, "A reappraisal of stroke mortality trends in Brazil (1979-2009)," International Journal of Stroke, vol. 8, no. 3, pp. 155-163, 2013.

[4] C. R. Garritano, P. M. Luz, M. L. E. Pires, M. T. S. Barbosa, and K. M. Batista, "Analysis of the mortality trend due to cerebrovascular accident in Brazil in the XXI century," Arquivos Brasileiros de Cardiologia, vol. 98, no. 6, pp. 519-527, 2012.

[5] L. Copstein, J. G. Fernandes, and G. A. N. Bastos, "Prevalence and risk factors for stroke in a population of Southern Brazil," Arquivos de Neuro-Psiquiatria, vol. 71, no. 5, pp. 294-300, 2013.

[6] I. M. Abe, P. A. Lotufo, A. C. Goulart, and I. M. Benseñor, "Stroke prevalence in a poor neighbourhood of São Paulo, Brazil: applying a stroke symptom questionnaire," International Journal of Stroke, vol. 6, no. 1, pp. 33-39, 2011.

[7] J. J. F. de Carvalho, M. B. Alves, G. Á. A. Viana et al., "Stroke epidemiology, patterns of management, and outcomes in Fortaleza, Brazil: a hospital-based multicenter prospective study," Stroke, vol. 42, no. 12, pp. 3341-3346, 2011.

[8] T. G. Fernandes, A. C. Goulart, T. F. Campos et al., "Early stroke case-fatality rates in three hospital registries in the Northeast and Southeast of Brazil," Arquivos de Neuro-Psiquiatria, vol. 70, no. 11, pp. 869-873, 2012.

[9] C. L. R. C. Rolim and M. Martins, "Quality of care for ischemic stroke in the Brazilian Unified National Health System," Cadernos de Saude Publica, vol. 27, no. 11, pp. 2106-2116, 2011.

[10] C. H. Moro, A. R. Gon $\tau$ alves, A. L. Longo et al., "Trends of the incidence of ischemic stroke thrombolysis over seven years and one-year outcome: a population-based study in Joinville, Brazil," Cerebrovascular Diseases Extra, vol. 3, pp. 156-166, 2013.

[11] C. Lei, B. Wu, M. Liu et al., "Totaled health risks in vascular events score predicts clinical outcomes in patients with cardioembolic and other subtypes of ischemic stroke," Stroke, vol. 45, pp. 1689-1694, 2014.

[12] C. Weimar, I. R. König, K. Kraywinkel, A. Ziegler, and H. C. Diener, "Age and National Institutes of Health Stroke Scale score within 6 hours after onset are accurate predictors of outcome 
after cerebral ischemia: development and external validation of prognostic models," Stroke, vol. 35, no. 1, pp. 158-162, 2004.

[13] G. Saposnik, A. K. Guzik, M. Reeves, B. Ovbiagele, and S. C. Johnston, "Stroke Prognostication using age and NIH Stroke Scale: SPAN-100," Neurology, vol. 80, no. 1, pp. 21-28, 2013.

[14] A. C. Flint, S. P. Cullen, B. S. Faigeles, and V. A. Rao, "Predicting long-term outcome after endovascular stroke treatment: the totaled health risks in vascular events score," American Journal of Neuroradiology, vol. 31, no. 7, pp. 1192-1196, 2010.

[15] A. C. Flint, B. Xiang, R. Gupta et al., “THRIVE score predicts outcomes with a third-generation endovascular stroke treatment device in the TREVO-2 trial," Stroke, vol. 44, no. 12, pp. 3370-3375, 2013.

[16] G. Ntaios, M. Faouzi, J. Ferrari, W. Lang, K. Vemmos, and P. Michel, "An integer-based score to predict functional outcome in acute ischemic stroke: the ASTRAL score," Neurology, vol. 78, no. 24, pp. 1916-1922, 2012.

[17] R. L. Sacco, S. E. Kasner, J. P. Broderick et al., "An updated definition of stroke for the 21st century: a statement for healthcare professionals from the American heart association/American stroke association," Stroke, vol. 44, no. 7, pp. 2064-2089, 2013.

[18] R. A. Valiente, M. Araújo de Miranda-Alves, G. Sampaio Silva et al., "Clinical features associated with early hospital arrival after acute intracerebral hemorrhage: challenges for new trials," Cerebrovascular Diseases, vol. 26, no. 4, pp. 404-408, 2008.

[19] J. C. Hemphill, D. C. Bonovich, L. Besmertis, G. T. Manley, and S. C. Johnston, "The ICH score: a simple, reliable grading scale for intracerebral hemorrhage," Stroke, vol. 32, pp. 891-897, 2001.

[20] A. M. Rowat, M. S. Dennis, and J. M. Wardlaw, "Hypoxaemia in acute stroke is frequent and worsens outcome," Cerebrovascular Diseases, vol. 21, no. 3, pp. 166-172, 2006.

[21] M. Lou, A. Safdar, M. Mehdiratta et al., "The HAT score: a simple grading scale for predicting hemorrhage after thrombolysis," Neurology, vol. 71, no. 18, pp. 1417-1423, 2008.

[22] D. Strbian, A. Meretoja, F. J. Ahlhelm et al., "Predicting outcome of IV thrombolysis-treated ischemic stroke patients: the DRAGON score," Neurology, vol. 78, no. 6, pp. 427-432, 2012.

[23] B. M. Kissela, J. C. Khoury, K. Alwell et al., "Age at stroke: temporal trends in stroke incidence in a large, biracial population," Neurology, vol. 79, no. 17, pp. 1781-1787, 2012.

[24] D. Chiu, L. Peterson, M. S. Elkind, J. Rosand, L. M. Gerber, and M. D. Silverstein, "Glycine Antagonist in Neuroprotection Americas Trial Investigators. Comparison of outcomes after intracerebral hemorrhage and ischemic stroke," Journal of Stroke and Cerebrovascular Diseases, vol. 19, pp. 225-229, 2010.

[25] G. C. Fonarow, E. E. Smith, J. L. Saver et al., "Timeliness of tissue-type plasminogen activator therapy in acute ischemic stroke: patient characteristics, hospital factors, and outcomes associated with door-to-needle times within 60 minutes," Circulation, vol. 123, no. 7, pp. 750-758, 2011.

[26] K. A. LaBresh, M. J. Reeves, M. R. Frankel, D. Albright, and L. H. Schwamm, "Hospital treatment of patients with ischemic stroke or transient ischemic attack using the "get with the guidelines" program," Archives of Internal Medicine, vol. 168, no. 4, pp. 411417, 2008.

[27] L. H. Schwamm, G. C. Fonarow, M. J. Reeves et al., "Get With the Guidelines-Stroke is associated with sustained improvement in care for patients hospitalized with acute stroke or transient ischemic attack," Circulation, vol. 119, no. 1, pp. 107-115, 2009.
[28] F. A. de Carvalho, L. H. Schwamm, G. W. Kuster, M. Bueno Alves, M. Cendoroglo Neto, and G. Sampaio Silva, "Get with the guidelines stroke performance indicators in a Brazilian tertiary hospital," Cerebrovascular Diseases Extra, vol. 2, pp. 26-35, 2012.

[29] Y. Xian, R. G. Holloway, W. Pan, and E. D. Peterson, "Challenges in assessing hospital-level stroke mortality as a quality measure: comparison of ischemic, intracerebral hemorrhage, and total stroke mortality rates," Stroke, vol. 43, no. 6, pp. 1687-1690, 2012. 


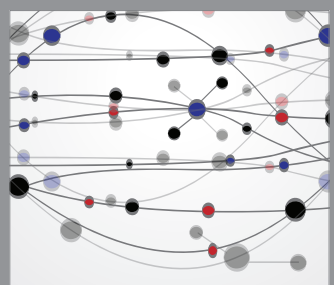

The Scientific World Journal
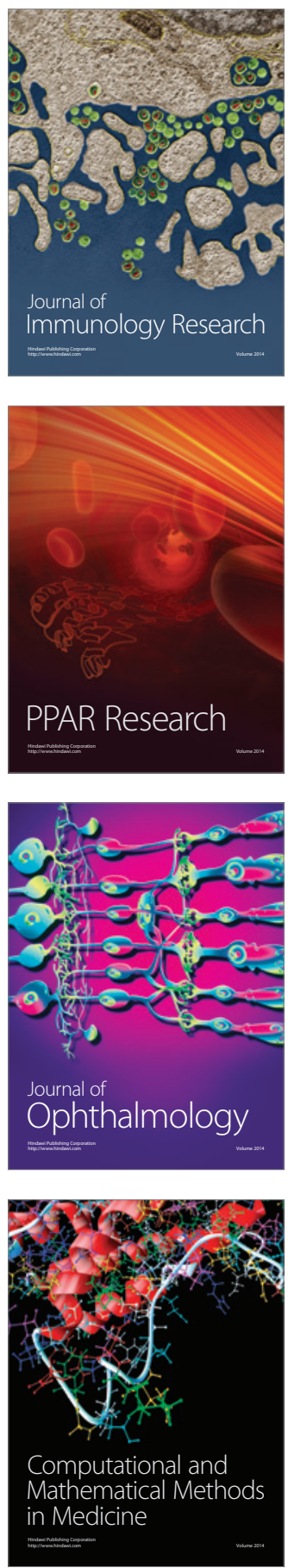

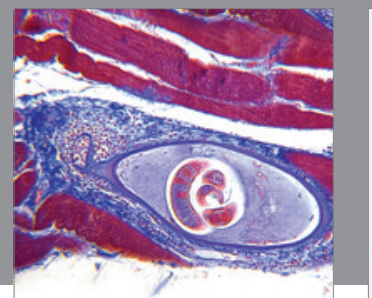

Gastroenterology

Research and Practice
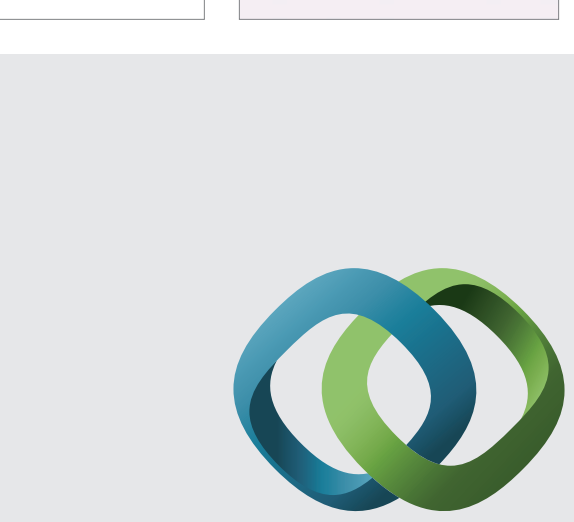

\section{Hindawi}

Submit your manuscripts at

http://www.hindawi.com
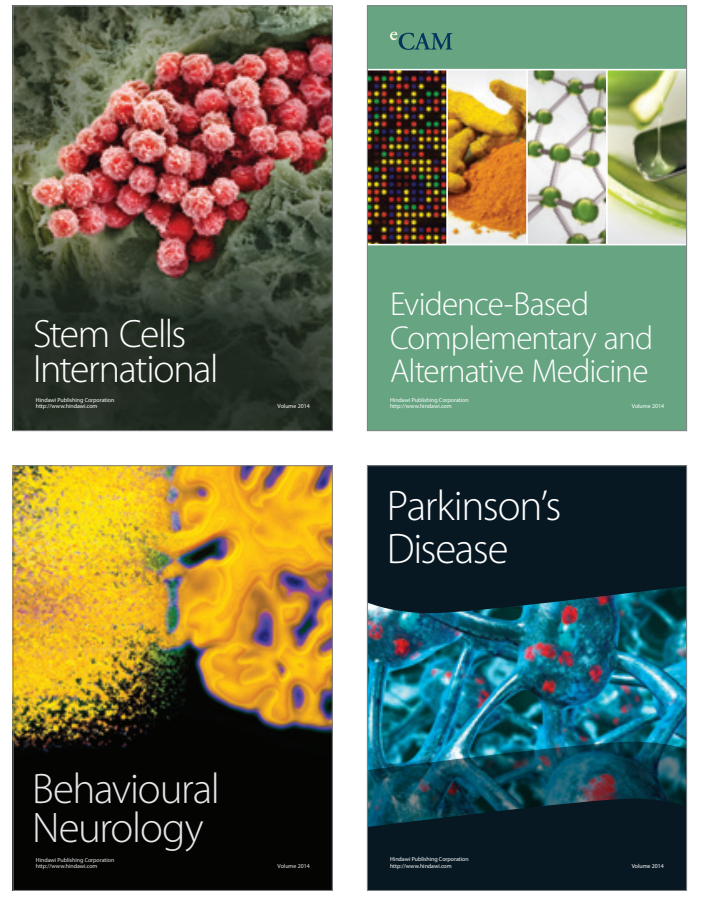
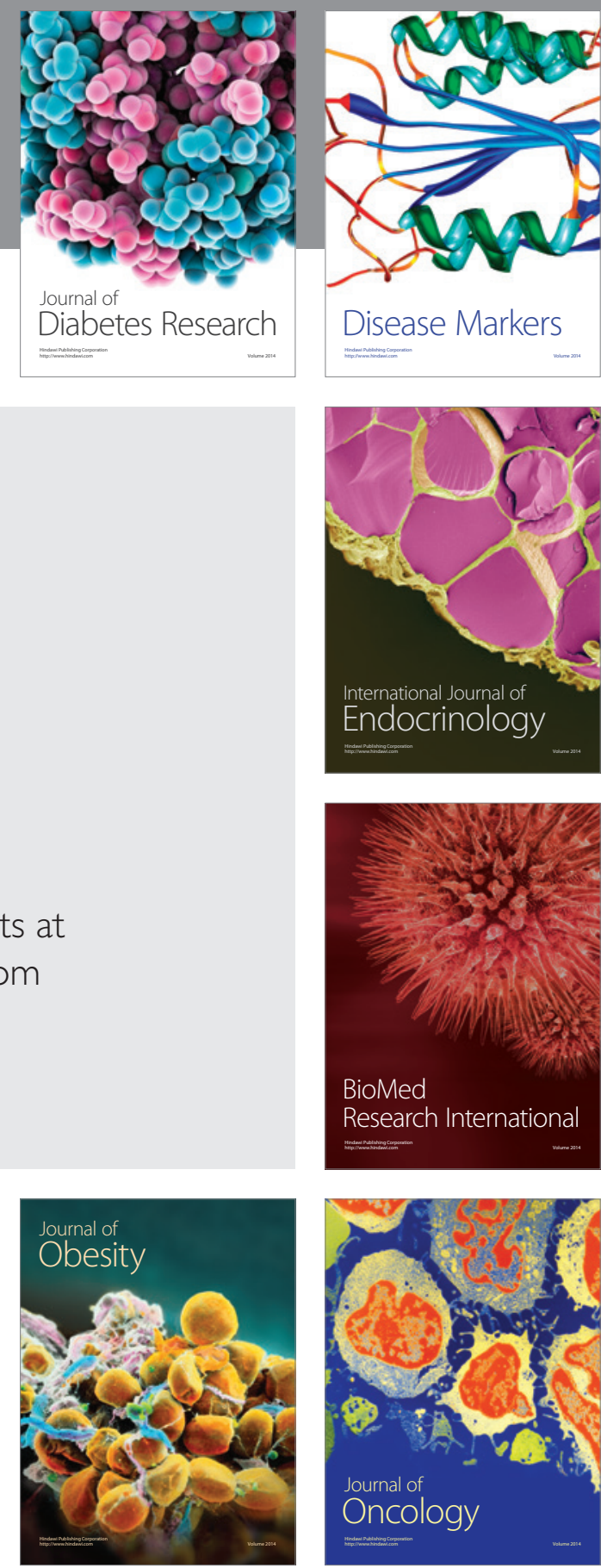

Disease Markers
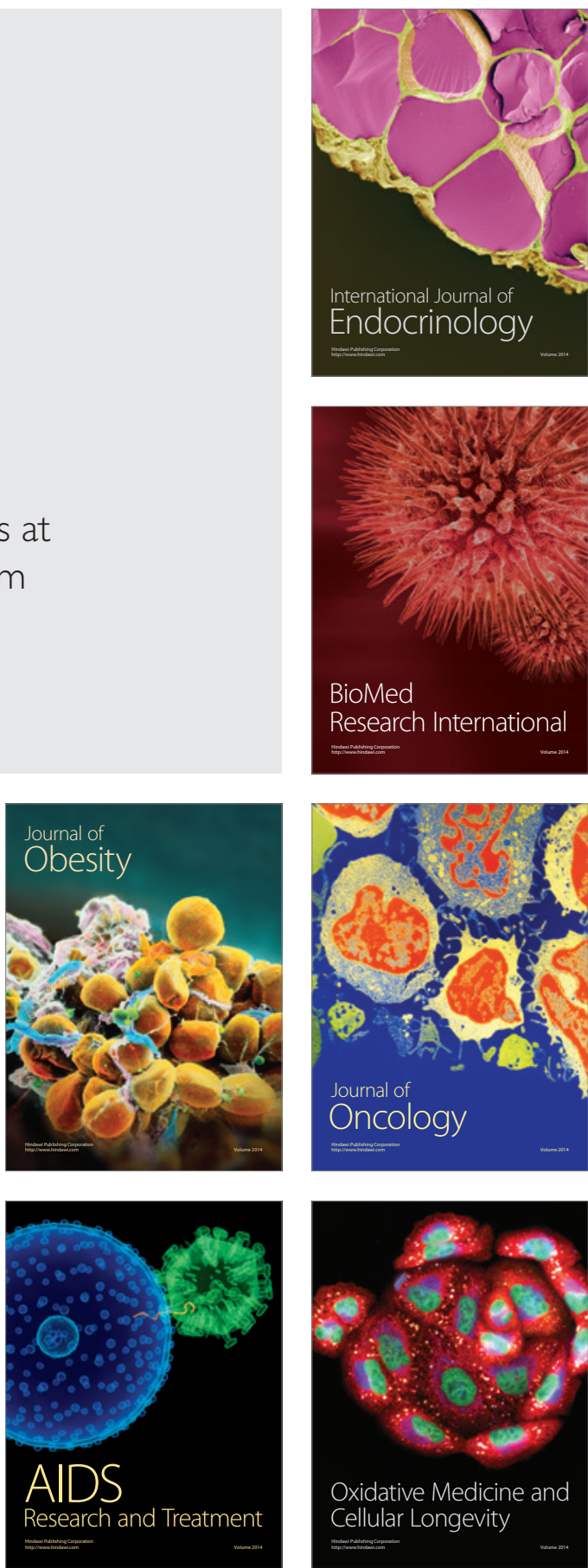